Objectives: To determine efficacy based on pooled data from 2 pivotal Phase 3 studies of tofacitinib in patients (pts) with active PsA.

Methods: Data were pooled from 2 placebo (PBO)-controlled, double-blind, multicentre, global Phase 3 studies (OPAL Broaden [N=422; 12 months; NCT01877668]; OPAL Beyond [N=394; 6 months; NCT01882439]). Pts had active PsA and either inadequate response (IR) to $\geq 1$ conventional synthetic disease-modifying antirheumatic drug (csDMARD) and were tumour necrosis factor inhibitor (TNFi)-naïve (OPAL Broaden), or had IR to $\geq 1$ TNFi (OPAL Beyond). Pts were randomised to tofacitinib $5 \mathrm{mg}$ twice daily (BID), $10 \mathrm{mg} \mathrm{BID,}$ adalimumab $40 \mathrm{mg}$ subcutaneous injection once every 2 weeks (OPAL Broaden only) or PBO, in addition to a single, stable background csDMARD. PBO pts advanced to tofacitinib $5 \mathrm{mg}$ or $10 \mathrm{mg} \mathrm{BID}$ at Month (M)3. Endpoints included ACR20/50/70 response rates ( $\geq 20 \%, \geq 50 \%$ and $\geq 70 \%$ improvement), change from baseline $(\Delta)$ in HAQ-DI (Health Assessment Questionnaire-Disability Index), HAQ-DI response (decrease from baseline [BL] of $>0.35$ ), PASI75 $(\geq 75 \% \mathrm{im}-$ provement from BL in Psoriasis Area and Severity Index), $\triangle \mathrm{LEI}$ (Leeds Enthesitis Index) and enthesitis absence, $\triangle \mathrm{DSS}$ (Dactylitis Severity Score) and dactylitis absence and $\triangle \mathrm{DLQI}$ (Dermatology Life Quality Index). Pooled data only included tofacitinib $5 \mathrm{mg}$ and $10 \mathrm{mg}$ BID (to M6) and PBO (to M3). Significance was declared for $p \leq 0.05$ without correction for multiplicity.

Results: For pooled data, pts were predominantly white $(94.2 \%)$ and female $(55.4 \%)$ with $\geq 5$ peripheral swollen or tender joints $(98.0 \%$ ), enthesitis (LEI $>0$; $67.5 \%$ ), dactylitis (DSS $>0 ; 52.5 \%$ ), psoriatic body surface area $\geq 3 \%(67.7 \%)$ and CRP levels above the upper limit of normal (>2.87 mg/L; $62.5 \%)$ at BL. Mean age was 49.1 years and PsA duration was 8.0 years. Significant improvements vs $\mathrm{PBO}$ at $\mathrm{M} 3$ were observed for peripheral arthritis and physical function endpoints for tofacitinib $5 \mathrm{mg}$ and $10 \mathrm{mg}$ BID: ACR20, ACR50, ACR70, $\triangle$ HAQ-DI (least squares mean [LSM]), and HAQ-DI response (Table 1). Significant improvements in psoriasis, enthesitis and dactylitis endpoints vs PBO were also observed for tofacitinib $5 \mathrm{mg}$ and $10 \mathrm{mg} \mathrm{BID}$ at M3: PASI75, $\triangle \mathrm{LEI}$, enthesitis absence based on LEI, $\triangle \mathrm{DSS}$ (LSM), dactylitis absence based on DSS and $\triangle \mathrm{DLQI}$ (Table 1). Efficacy was maintained or further improved at M6.

Table 1. Efficacy endpoints at Month 3 and Month 6; pooled data from OPAL Broaden and OPAL Beyond (Full

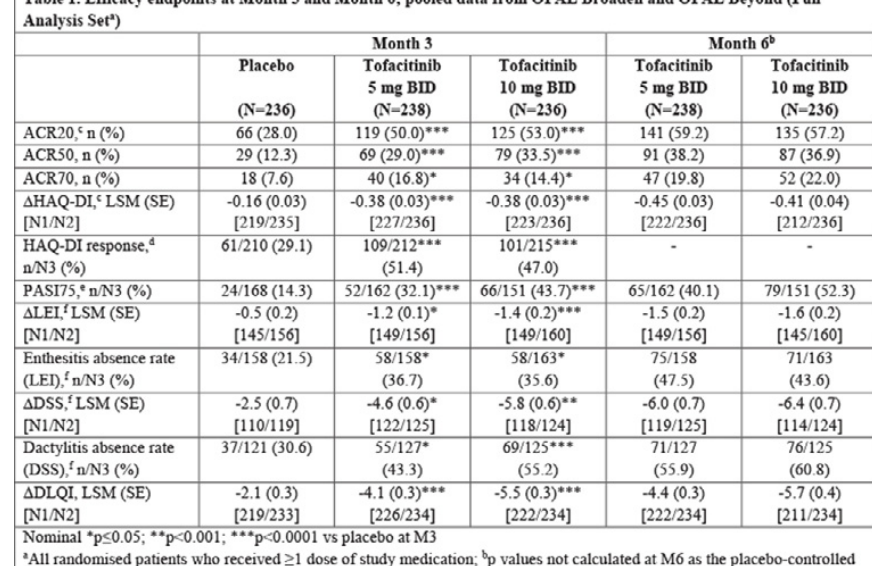
${ }^{2}$ All randomised patients who received $\geq 1$ dose of study medication; $; p$ values not calculated at $M 6$ as the placebo-controlled
period ended at M3; ' primary endpoint in each individual study at M3; damong patients with baseline HAQ-DI $\geq 0.35$ (analysis

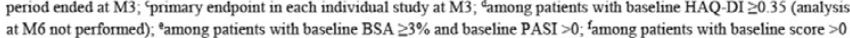
Large sample approximation to the difference in binomial proportions was used to analyse ACR20/50/70, HAQ-DI response, enthesitis absence, dactylitis absence and PASI75; missing response considered as non-response. $\triangle \mathrm{HAQ}-\mathrm{DI}, \triangle \mathrm{LEI}, \triangle \mathrm{DSS}$, and $\triangle D L Q I$ were analysed with a mixed model for repeated measures without imputation for missing values

$\triangle$, change from baseline; ACR20/50/70, American College of Rheumatology $\geq 20 / 50 / 70 \%$ improvement; BID twice daily; BSA, body surface area; DLQI, Dermatology Life Quality Index; DSS, Dactylitis Severity Score; HAQ-DI, Health
Assessment Questionnaire-Disability Index, LEI, Leeds Enthesitis Index; LSM, least squares mean; M, Month; N, number of Assessment Questionnaire-Disability Index; LEI, Leeds Enthesitis Index; LSM, least squares mean; M, Month; N, number of patients in the Full Analysis Set, $\mathrm{n}$, number of patients with response; $\mathrm{N} 1$, number of patients evaluable at a visit; $\mathrm{N} 2$, num of patients included in the model; N3, number of patients evaluable at a visit (denominator); PAS1, Psoriasis Area and Severity Index; PASI75, $\geq 75 \%$ improvement from baseline PASI; SE, standard erro

Conclusions: In a pooled analysis of csDMARD-IR/TNFi-naïve and TNFi-IR pts, tofacitinib $5 \mathrm{mg}$ and $10 \mathrm{mg}$ BID were superior to PBO at M3 across four PsA disease domains: peripheral arthritis, psoriasis, enthesitis and dactylitis.

Acknowledgements: This study was sponsored by Pfizer Inc. Editorial support was provided by $\mathrm{K}$ Haines of $\mathrm{CMC}$ and was funded by Pfizer Inc.

Disclosure of Interest: P. Nash Grant/research support from: AbbVie, Amgen, Bristol-Myers Squibb, Celgene, Janssen, Eli Lilly, Novartis, Pfizer Inc, Roche, UCB, Consultant for: AbbVie, Amgen, Bristol-Myers Squibb, Celgene, Janssen, Eli Lilly, Merck, Novartis, Pfizer Inc, Sanofi, Roche, UCB, Speakers bureau: AbbVie, Amgen, Bristol-Myers Squibb, Celgene, Janssen, Novartis, Pfizer Inc, Roche, UCB, L. Coates Speakers bureau: Pfizer Inc, R. Fleischmann Grant/research support from: Abbott, Amgen, Astellas, Bristol-Myers Squibb, Boehringer Ingelheim, Celgene, Genentech, Eli Lilly, Janssen, Novartis, Pfizer Inc, Regeneron, Sanofi Aventis, Roche, UCB, Consultant for: Abbott, Akros, Amgen, Bristol-Myers Squibb, Celgene, Genentech, Eli Lilly, Janssen, Novartis, Pfizer Inc, Sanofi Aventis, UCB, K. Papp Grant/research support from: Abbott, Amgen, Anacor, Astellas, Celgene, Celtic, Dow Pharma, Eli Lilly, Galderma, Janssen, Janssen Biotech (Centocor), Merck, Novartis, Pfizer Inc, Consultant for: 3M, Abbott, Akros, Alza, Amgen, Astellas, Baxter, Boehringer Ingelheim, Celgene, Cipher, Eli Lilly, Forward Pharma, Funxional Therapeutics, Galderma, Genentech, Isotechnika, Janssen, Janssen Biotech (Centocor), J\&J, Kirin, Kyowa, Meiji Seika Pharma, Merck, Mitsubishi Pharma, Mylan, Novartis, Pfizer Inc, Regeneron, Sanofi Aventis, Serono, Stiefel, Takeda, UCB, Speakers bureau: 3M, Abbott, Amgen, Astellas, Boehringer Ingelheim, Celgene, Eli Lilly, Galderma, Janssen, Merck, Novartis, Pfizer Inc, J. Gomez-Reino Grant/research support from: AbbVie, Novartis, Pfizer Inc, Roche, UCB, Consultant for: Pfizer Inc, Speakers bureau: AbbVie, Bristol-Myers Squibb, Janssen, MSD, Pfizer Inc, Roche, UCB, K. Kanik Shareholder of: Pfizer Inc, Employee of: Pfizer Inc, C. Wang: None declared, J. Wu Shareholder of: Pfizer Inc, Employee of: Pfizer Inc, T. Hendrikx Shareholder of: Pfizer Inc, Employee of: Pfizer Inc, W. Ports Shareholder of: Pfizer Inc, Employee of: Pfizer Inc

DOI: 10.1136/annrheumdis-2017-eular.2444

\section{SAT0470 SECUKINUMAB PROVIDES SUSTAINED IMPROVEMENTS IN THE SIGNS AND SYMPTOMS OF ACTIVE PSORIATIC ARTHRITIS: 3-YEAR EFFICACY AND SAFETY RESULTS FROM PHASE 3 FUTURE 1 TRIAL}

P.J. Mease ${ }^{1}$, A. Kavanaugh ${ }^{2}$, A. Reimold ${ }^{3}$, H. Tahir $^{4}$, J. Rech ${ }^{5}$, S. Hall ${ }^{6}$, P. Geusens $^{7,8}$, P. Pascale ${ }^{9}$, E.M. Delicha ${ }^{9}$, L. Pricop ${ }^{10}$, S. Mpofu ${ }^{9}$ on behalf of the FUTURE 1 study group. ${ }^{1}$ Swedish Medical Centre and University of Washington, Seattle; ${ }^{2}$ UC San Diego School of Medicine, la Jolla; ${ }^{3}$ University of Texas Southwestern Medical Center, Dallas, United States; ${ }^{4}$ Barts Health NHS Trust, London, United Kingdom; ${ }^{5}$ University of Erlangen-Nuremberg, Erlangen, Germany; ${ }^{6}$ Monash University, Melbourne, Australia; ${ }^{7}$ University of Hasselt, Hasselt, Belgium; ${ }^{8}$ Maastricht University Hospital, Maastricht, Netherlands; ${ }^{9}$ Novartis Pharma AG, Basel, Switzerland; ${ }^{10}$ Novartis Pharmaceuticals Corporation, East Hannover, United States

Background: Secukinumab significantly improved the signs and symptoms of psoriatic arthritis (PsA) over 2 years (yrs) in the FUTURE 1 study. ${ }^{1}$

Objectives: To report efficacy and safety of secukinumab through 3 yrs in an extension of the FUTURE 1 study (NCT01892436).

Methods: After 2-yr core trial, patients (pts) receiving secukinumab 150/75mg s.c. entered the 3-yr extension phase. Efficacy results at Week (Wk) 156 are presented for those pts originally randomised to secukinumab $(n=308)$ and included ACR20/50/70, PASI 75, DAS28-CRP, SF-36 PCS, HAQ-DI, dactylitis and enthesitis. Multiple imputation was used for analysis of binary variables while continuous variables are reported as observed. Analyses by anti-TNF status (naïve/inadequate response) were prespecified and reported as observed. Safety analysis included all pts $(n=587)$ who received $\geq 1$ dose of secukinumab.

Results: Overall, 457 of the original 606 pts entered the extension study of which $435(95.2 \%)$ pts completed 156 wks (151 [93.8\%] pts in IV $\rightarrow 150 \mathrm{mg}$ group; 142 [96.6\%] in IV $\rightarrow 75 \mathrm{mg}$ group; 142 [95.3\%] in PBO $\rightarrow$ secukinumab groups). Sustained clinical improvements through Wk 156 were observed across all endpoints and were seen regardless of prior anti-TNF use (Table 1). Over

Abstract SAT0470 - Table 1. Summary of efficacy results at Week 156

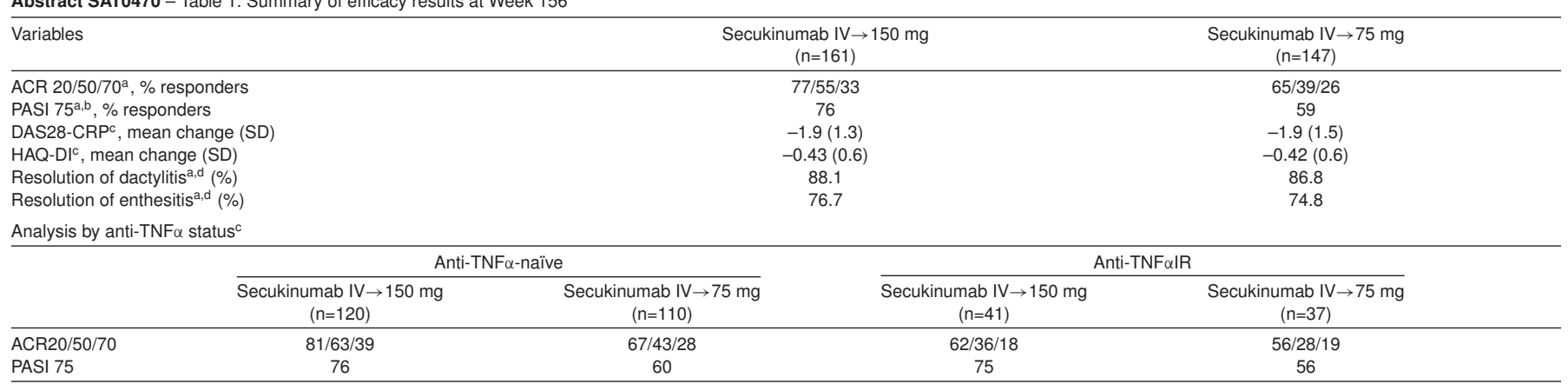

a Multiple imputation (missing binary variables). ${ }^{\mathrm{b}}$ Analysis performed in pts with psoriasis $\geq 3 \%$ body surface area at time of randomisation ( $\mathrm{n}=89$ and $\mathrm{n}=82$ in secukinumab IV $\rightarrow 150$ and IV $\rightarrow 75$ mg,

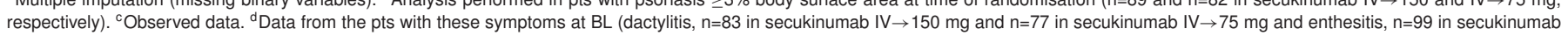
$\mathrm{IV} \rightarrow 150 \mathrm{mg}$ and $\mathrm{n}=91$ in secukinumab IV $\rightarrow 75 \mathrm{mg}$ ). $\mathrm{n}$, number of pts in the extension study. 
the entire study period (mean $[ \pm S D]$ exposure to secukinumab of $1025.1 \pm 372.7$ days), the exposure-adjusted incidence rate with secukinumab for serious infections/infestations, candida infections, Crohn's disease, and malignant/unspecified tumors was 1.7 (27), 1.2 (17), 0.1 (2), and 0.9 (14) per 100 pt-yrs, respectively. Conclusions: Secukinumab provided sustained improvements in signs/symptoms and across multiple clinical domains of active PsA in pts who completed $3 \mathrm{yrs}$ of therapy. Secukinumab was well tolerated with a favorable safety profile consistent with that previously reported. ${ }^{1}$

References:

[1] Kavanaugh A, et al. Arthritis Care Res. (Hoboken) 2016

Disclosure of Interest: P. Mease Grant/research support from: Abbvie, Amgen, BMS, Celgene, Crescendo Bioscience, Genentech, Janssen, Lilly, Merck, Novartis, Pfizer, UCB, Consultant for: Abbvie, Amgen, BMS, Celgene, Crescendo Bioscience, Genentech, Janssen, Lilly, Merck, Novartis, Pfizer, UCB, Speakers bureau: Abbvie, Amgen, BMS, Celgene, Crescendo Bioscience, Genentech, Janssen, Lilly, Merck, Novartis, Pfizer, UCB, A. Kavanaugh Consultant for: Novartis, A. Reimold Grant/research support from: AbbVie, H. Tahir Speakers bureau: Novartis, Eli Lilly, and Abbvie, J. Rech Speakers bureau: Abbvie, BMS, Celgene, Fresenius, medicap, MSD, Novartis, Pfizer, and Roche, S. Hall: None declared, P. Geusens Grant/research support from: Pfizer, Abbott, Lilly, Amgen, MSD, Will, Bio Minerals and Roche, Speakers bureau: Pfizer, Abbott, Lilly, Amgen, MSD, Will, Bio Minerals and Roche, P. Pascale Shareholder of: Novartis, Employee of: Novartis, E. M. Delicha Employee of: Novartis, L. Pricop Shareholder of: Novartis, Employee of: Novartis, S. Mpofu Shareholder of: Novartis, Employee of: Novartis DOI: 10.1136/annrheumdis-2017-eular.1260

\section{SAT0471 TRENDS IN CLINICAL CHARACTERISTICS ASSOCIATED WITH ACHIEVEMENT OF MINIMAL DISEASE ACTIVITY IN RESPONSE TO BIOLOGIC THERAPY IN PSORIATIC ARTHRITIS - ANALYSES FROM THE CORRONA PSORIATIC ARTHRITIS/SPONDYLOARTHRITIS (PSA/SPA) REGISTRY}

P.J. Mease ${ }^{1}$, C. Karki ${ }^{2}$, M. Liu ${ }^{2}$, A. Kavanaugh ${ }^{3}$, C.T. Ritchlin ${ }^{4}$, D.H. Hunyh ${ }^{5}$, R. Pandurengan ${ }^{2}$, J.B. Palmer ${ }^{6}$, J.D. Greenberg $2,7 .{ }^{1}$ Seattle Rheumatology Associates, Seattle, WA; ${ }^{2}$ Corrona, LLC, Southborough, MA; ${ }^{3}$ University of California San Diego, San Diego, CA: ${ }^{4}$ University of Rochester, Rochester, NY; ${ }^{5}$ Scripps Institute, la Jolla, CA; ${ }^{6}$ Novartis, East Hanover, $\mathrm{NJ} ;{ }^{7}$ New York University School of Medicine, New York, NY, United States

Background: Achievement of minimal disease activity (MDA) may represent an objective target for treatment for patients with psoriatic arthritis (PsA). ${ }^{1}$ A patient is considered to have achieved MDA when 5 of the following 7 criteria are met: tender joint count (TJC) $\leq 1$, swollen joint count (SJC) $\leq 1$, affected body surface area $(B S A) \leq 3 \%$, patient pain VAS $\leq 15$, patient global activity VAS $\leq 20, \mathrm{HAQ}$ score $\leq 0.5$ and tender entheseal points $\leq 1 .{ }^{1}$

Objectives: To retrospectively report the MDA and patient-reported outcomes (PROs) over time (baseline vs first follow-up [FU] visit vs second FU visit) that may contribute to achievement of MDA in responders versus non-responders to biologic treatment.

Methods: This analysis included all patients with PsA in the Corrona registry aged $\geq 18$ years between March 2013 and March 2016 who received biologics (index biologics) at enrollment (baseline) and had $\geq 2 \mathrm{FU}$ visits (at $\approx 6$-month intervals, mean [SD] 2nd FU visit: 15.7 [3.7] months). Responders were defined as patients who achieved MDA at the second FU visit and remained on their index biologic. Demographics, clinical characteristics, PROs and treatment history were collected at enrollment and at both FU visits. Trend tests of MDA over time were performed using the Wilcoxon rank-sum nonparametric test for responders and non-responders separately.

Results: Of 148 patients who met the inclusion criteria (mean [SD] age, 54.7 [11.0] years; mean [SD] disease duration, 11.8 [10.1] years), 34 patients (23\%) were classified as responders and 114 patients $(77 \%)$ were non-responders at the second FU visit. The core components of MDA in these patients are shown in Table 1. Among responders, there were significant improvements in clinical characteristics and PROs such as mean TJC ( 3.4 vs 2.1 vs $0.6 ; P=0.004$ ), SJC (2.5 vs 0.8 vs $0.5 ; P<0.0001)$, percentage of affected BSA $(5.6 \%$ vs $2.4 \%$ vs $1.4 \% ; P=0.03)$, patient pain (34.7 vs 26.1 vs $21.9 ; P=0.007)$ and HAQ scores $(0.6$ vs 0.4 vs $0.3 ; P=0.04)$; however, there were no significant changes over time for patient global assessment or enthesitis counts $(P>0.05)$. Non-responders failed to have a significant improvement from baseline to the first and second FU visits in TJC, SJC, enthesitis, pain, patient global assessment and percentage of affected BSA (all $P>0.05$ )

Conclusions: Only $23 \%$ of patients achieved MDA on their index biologic at the second FU visit and were considered responders. Over time, responders showed significant improvements in TJC and SJC, percentage of affected BSA, patient pain and HAQ scores; these most likely contributed to achievement of MDA response. A treat-to-target approach may be considered given the low number of patients in MDA.

References:

[1] Coates, LC et al. Ann Rheum Dis. 2010;69(1):48-53.

Acknowledgements: Corrona, LLC, has been supported through contracted subscriptions in the last 2 years by AbbVie, Amgen, BMS, Crescendo, Eli Lilly and Company, GSK, Horizon Pharma USA, Janssen, Momenta Pharmaceuticals, Novartis, Pfizer, Roche and UCB.
Table 1. Clinical and patient-reported characteristics of patients with PsA in the Corrona registry stratified by response to index biologics over time

\begin{tabular}{|c|c|c|c|c|c|c|c|c|}
\hline \multirow[b]{2}{*}{ Characteristics $^{*}$} & \multicolumn{2}{|c|}{ At Enrollment } & \multicolumn{2}{|c|}{ 1st FU Visit } & \multicolumn{2}{|c|}{ 2nd FU Visit } & \multirow{2}{*}{$\begin{array}{c}P \\
\text { Value } \\
(R)\end{array}$} & \multirow{2}{*}{$\begin{array}{c}P \\
\text { Value } \\
\text { (NR) }\end{array}$} \\
\hline & $\begin{array}{c}R \\
n=34\end{array}$ & $\begin{array}{c}N R \\
n= \\
114\end{array}$ & $\begin{array}{c}R \\
n=34\end{array}$ & $\begin{array}{l}N R \\
n= \\
114\end{array}$ & $\begin{array}{c}R \\
n=34\end{array}$ & $\begin{array}{l}N R \\
n= \\
114\end{array}$ & & \\
\hline MDA, $n(\%)^{\dagger}$ & $\begin{array}{l}0 \\
\text { (0) }\end{array}$ & $\begin{array}{l}0 \\
0 \\
(0)\end{array}$ & $\begin{array}{c}17 \\
(57)\end{array}$ & $\begin{array}{c}13 \\
(14)\end{array}$ & $\begin{array}{c}34 \\
(100)\end{array}$ & $\begin{array}{c}10 \\
(8.8)\end{array}$ & $\begin{array}{c}< \\
0.0001\end{array}$ & 0.01 \\
\hline $\begin{array}{l}\text { Tender joint count (0- } \\
68 \text { ) }\end{array}$ & $\begin{array}{l}3.4 \\
(5.3)\end{array}$ & $\begin{array}{c}7.2 \\
(11.0)\end{array}$ & $\begin{array}{c}2.1 \\
(5.1)\end{array}$ & $\begin{array}{l}6.0 \\
(8.2)\end{array}$ & $\begin{array}{c}0.6 \\
0.4)\end{array}$ & $\begin{array}{c}6.6 \\
(11.7)\end{array}$ & 0.004 & 0.16 \\
\hline $\begin{array}{l}\text { Swollen joint count (0- } \\
66 \text { ) }\end{array}$ & $\begin{array}{l}2.5 \\
(3.5)\end{array}$ & $\begin{array}{l}2.8 \\
(3.7)\end{array}$ & $\begin{array}{c}0.8 \\
(1.7)\end{array}$ & $\begin{array}{l}2.5 \\
(4.5)\end{array}$ & $\begin{array}{c}1.7) \\
0.5 \\
(1.5)\end{array}$ & $\begin{array}{l}2.3 \\
(3.9)\end{array}$ & $\begin{array}{c}< \\
0.0001\end{array}$ & 0.12 \\
\hline $\begin{array}{l}\text { SPARCC enthesitis (0- } \\
16 \text { ) }\end{array}$ & $\begin{array}{l}2.01 \\
2.4 \\
(0.5)\end{array}$ & $\begin{array}{l}(3.1) \\
4.4 \\
(3.3)\end{array}$ & $\begin{array}{l}3.1) \\
3.0 \\
(2.8)\end{array}$ & $\begin{array}{l}(7.0) \\
4.1 \\
(3.3)\end{array}$ & $\begin{array}{l}(1.0) \\
(1.4)\end{array}$ & $\begin{array}{l}3.97 \\
(1.9)\end{array}$ & 0.70 & 0.67 \\
\hline BSA, $\%$ & 5.6 & $\begin{array}{c}8.3 \\
14.4)\end{array}$ & 2.4 & 5.1 & 1.4 & 4.8 & 0.03 & 0.006 \\
\hline $\begin{array}{l}\text { Patient-reported pain } \\
\text { (VAS } 0-100 \text { ) }\end{array}$ & $\begin{array}{l}35.7 \\
(23.4)\end{array}$ & $\begin{array}{l}51.2 \\
(24.8)\end{array}$ & $\begin{array}{l}26.1 \\
(25.2)\end{array}$ & $\begin{array}{l}54.6 \\
(26.3)\end{array}$ & $\begin{array}{c}21.9 \\
(20.5)\end{array}$ & $\begin{array}{l}54.6 \\
(25.3)\end{array}$ & 0.007 & 0.28 \\
\hline $\begin{array}{l}\text { Patient global } \\
\text { assessment (VAS 0- } \\
100 \text { ) }\end{array}$ & $\begin{array}{c}70 \\
(17.8)\end{array}$ & $\begin{array}{l}53.6 \\
(24.0)\end{array}$ & $\begin{array}{l}59.2 \\
(30.2)\end{array}$ & $\begin{array}{l}54.3 \\
(24.5)\end{array}$ & $\begin{array}{c}62 \\
(31.4)\end{array}$ & $\begin{array}{l}(20.0) \\
(22.5)\end{array}$ & 0.58 & 0.47 \\
\hline $\operatorname{HAQ}(0-3)$ & $\begin{array}{l}0.6 \\
(0.5)\end{array}$ & $\begin{array}{l}1.0 \\
(0.6)\end{array}$ & $\begin{array}{c}0.4 \\
(0.5)\end{array}$ & $\begin{array}{l}1.0 \\
(0.6)\end{array}$ & $\begin{array}{c}0.3 \\
(0.4)\end{array}$ & $\begin{array}{l}1.0 \\
(0.6)\end{array}$ & 0.04 & 0.54 \\
\hline
\end{tabular}

BSA, body surface area; FU, follow-up: $H A Q$, Health Assessment Questionnaire; MDA, minimal disease activity; NR, non-responders; R, responders; SPARCC, Spondyloarthritis Research Consortium of Canada; VAS, visual analog scale. "All values are presented as "mean (SD)" unless otherwise stated. gories tender joint count $\leq 1$, swollen joint count $\leq 1$
points $\leq 1$

Disclosure of Interest: P. Mease Grant/research support from: Celgene, Novartis, AbbVie, Amgen, BMS, Lilly, Pfizer, UCB, Consultant for: Celgene, Corrona, Novartis, AbbVie, Amgen, BMS, Crescendo, Genentech, Janssen, Lilly, Merck, Pfizer, UCB, C. Karki Employee of: Corrona, LLC, M. Liu Employee of: Corrona, LLC, A. Kavanaugh Grant/research support from: Amgen, AbbVie, Janssen, Pfizer, Novartis, C. Ritchlin Grant/research support from: Amgen, Janssen, UCB, Consultant for: AbbVie, Amgen, Janssen, Regeneron, UCB, D. Hunyh Speakers bureau: AbbVie, BMS, R. Pandurengan Employee of: Corrona, LLC, J. Palmer Employee of: Novartis, J. Greenberg Shareholder of: Corrona, LLC, Consultant for: Lilly, Genentech, Janssen, Novartis, Pfizer, Employee of: Corrona, LLC DOI: 10.1136/annrheumdis-2017-eular.1479

\section{SAT0472 UTILIZATION OF THE PSORIASIS EPIDEMIOLOGY SCREENING TOOL TO IDENTIFY SIGNS AND SYMPTOMS OF EARLY PSORIATIC ARTHRITIS AMONG THOSE WITH PSORIASIS: ANALYSIS FROM THE CORRONA PSORIASIS REGISTRY}

P.J. Mease ${ }^{1}$, J.B. Palmer ${ }^{2}$, M. Lebwohl ${ }^{3}$, C. Karki ${ }^{4}$, G.W. Reed ${ }^{4,5}$, C.J. Etzel ${ }^{4,6}$ J.D. Greenberg ${ }^{4,7}$, P.S. Helliwell ${ }^{8} .{ }^{1}$ Swedish Medical Center and University of Washington, Seattle; ${ }^{2}$ Novartis Pharmaceuticals Corporation, East Hanover; ${ }^{3}$ Icahn School of Medicine at Mount Sinai, New York; ${ }^{4}$ Corrona, LLC, Southborough; ${ }^{5}$ University of Massachusetts Medical School, Worcester; ${ }^{6}$ The University of Texas MD Anderson Cancer Center, Houston; ${ }^{7}$ New York University School of Medicine, New York, United States; ${ }^{8}$ University of Leeds, Leeds, United Kingdom

Background: The Psoriasis Epidemiology Screening Tool (PEST) is a 5-item questionnaire developed to help identify psoriatic arthritis (PsA) at an early stage, with a score $>3$ indicative of PsA. ${ }^{1}$ A recent Korean study found that a PEST score of 2 may be a more favorable cutoff for screening patients with psoriasis ( $\mathrm{PsO}$. ${ }^{2}$ Objectives: To assess the risk of undiagnosed PsA among patients with PsO and characterize patients based on PEST scores in a US cohort.

Methods: This study included all patients enrolled in the Corrona PsO Registry with data on all 5 PEST questions. Demographics, disease characteristics, patient-reported outcomes (PROs) and medication use were analyzed at the time of enrollment and stratified by PEST score $(0,1,2$ or $\geq 3)$. Pairwise comparisons were made between PEST score $=0$ (reference) and other PEST score groups using $t$-tests for continuous variables and $\chi^{2}$ tests for categorical variables.

Results: As of June 2016, 99.1\% (1516/1529) of patients in the Corrona PsO Registry had data on all 5 PEST questions; 612 patients $(40.4 \%)$ had dermatologist-reported PsA at enrollment. Among the remaining 904 patients, 421 patients $(46.6 \%)$ had a PEST score $=0,225(24.9 \%)$ had a PEST score $=1,146(16.2 \%)$ had a PEST score $=2$ and $112(12.4 \%)$ had a PEST score $>3$. Of patients with a PEST score $>3$, patients most commonly answered "yes" to "have you ever had a swollen joint (or joints)?" (89\%) and "has a doctor ever told you that you have arthritis?" (86\%). Compared with patients with a PEST score $=0$, patients with a PEST score $>1$ all had a higher BMI, longer duration of $\mathrm{PsO}$, increased family history of PsA, increased prevalence of nail PsO and worse EQ-VAS at enrollment (all $P<0.05$; Table 1). In addition, patients with PEST scores $>2$ were older, more likely to be female, less likely to be employed and had an increased family history of PsO, worse pain and fatigue, worse dermatology-related quality of life and higher percentage impairment of daily activities due to psoriasis at enrollment vs patients with a PEST score $=0$ (all $P<0.05)$. There were no significant differences across PEST scores in affected body surface area or PASI scores.

Conclusions: In this cohort of PsO patients with no diagnosis of PsA, patients with PEST scores $\geq 2$ were significantly different from those with PEST scores $=0$ 